\title{
A INFLUÊNCIA DAS VARIÁVEIS AMBIENTAIS E ORGANIZACIONAIS NO DESEMPENHO DE STARTUPS
}

DOI: 1014211/regepe.v5i1.256

Artigo recebido em:27/03/2015 Artigo aprovado em:29/01/2016

Juliana Queirós Miranda - Universidade de Brasília ${ }^{1}$ Carlos Denner Santos Júnior - Universidade de Brasília ${ }^{2}$ Alexandre Teixeira Dias - Universidade FUMEC ${ }^{3}$

Resumo: Os novos negócios de base inovadora e tecnológica, e as startups têm conferido uma alavancagem para a economia dos países. Apesar disso, as startups estão mais suscetíveis a fracassarem devido à sua vulnerabilidade inicial, considerando que enfrentam mais riscos, possuem menos recursos e têm pouca legitimidade. Dessa forma, identificou-se a relevância em analisar os fatores que influenciam no desempenho das startups através de variáveis ambientais e organizacionais e suas relações entre si e com o desempenho desses negócios inovadores. Desenvolveu-se assim um modelo teórico com base nas duas principais correntes téoricas da literatura de estratégia empresarial, isto é, considerando os fatores internos à organização e externos de seu ambiente. O método utilizado foi o levantamento (survey), enviado para mais de 700 startups em todo o Brasil, obtendo uma amostra válida de 92 respondentes. A análise dos dados foi baseada na modelagem de equações estruturais, realizada por meio do software SmartPLS. Os resultados indicaram ausência de significância estatística nas hipóteses analisadas, indicando que não há relação entre as variáveis ambientais e organizacionais e o desempenho das startups, potencialmente contribuindo para as teorias utilizadas e que, normalmente, foram desenvolvidas através da análise de grandes empreendimentos. Esta pesquisa busca, assim, contribuir para os estudos organizacionais, ao apresentar uma diferença relacionada com o desempenho no contexto das startups.

Palavras-chave: Atratividade; Incerteza Ambiental; Estrutura Organizacional; Tomada de Decisão; Experiência; Desempenho; Startups.

\footnotetext{
${ }^{1}$ Endereço: SHCGN 708, Bloco H, apt. 402. CEP: 70740768 - Brasília, DF. E-mail:

julianaqmiranda@gmail.com

2 E-mail: carlosdenner@gmail.com

${ }^{3}$ E-mail: alexandretdias@gmail.com
}

MIRANDA, J. Q.; SANTOS JUNIOR, C. D.; DIAS, A. T. A influência das variáveis ambientais e organizacionais no desempenho de startups. Revista de Empreendedorismo e Gestão de Pequenas Empresas, v.5, n.1, 2016. 


\title{
THE INFLUENCE OF ENVIRONMENTAL AND ORGANIZATIONAL VARIABLES IN STARTUPS PERFORMANCE
}

\begin{abstract}
The new businesses based in innovative and technology and the startups have provided leverage to the economy of countries. Nevertheless, startups are more susceptible to fail due to their liability of newness, facing more risks with fewer resources and little legitimacy. Therefore, it was identified the importance of analyzing the factors that influence the performance of startups through environmental and organizational variables and their relationships with each other and with the performance of these innovative businesses. The theoretical model was structured based on the two main theoretical business strategy literature, that is, considering both internal and external factors to the organization that interact to influence performance. The method used was a survey, which was sent to more than 700 startups around Brazil, obtaining the return of 92 valid respondents. Data analysis was based on structural equation modeling, performed through the software SmartPLS. The results showed no statistical significance in the analyzed cases, indicating that there is no relation between environmental and organizational variables and performance of startups, potentially contributing to the theories used and that normally were developed through the analysis of large enterprises. This research aims to contribute to organizational studies, presenting a related difference with the performance in the context of startups.
\end{abstract}

Keywords: Attractiveness; Environmental Uncertainty; Organizational Structure; Strategic Making Decisions; Experience; Performance; Startups.

\section{Introdução}

Os novos negócios relacionados à tecnologia vêm adquirindo cada vez mais destaque na economia dos países em todo o mundo. A competitividade de uma nação, na visão de Porter (1980), tem intensa relação com a capacidade de inovação de sua indústria e com a existência de organizações empreendedoras de base tecnológica.

Com propostas inovadoras de produtos ou serviços, os novos negócios têm proporcionado crescimento para a economia. Os empreendedores identificam e criam oportunidades no mercado através de inovações e, consequentemente, provocam novas formas de atuação organizacional nos mercados de alta tecnologia. Estes novos negócios de base inovadora e tecnológica, denominados também de startups, são o objeto de pesquisa deste estudo.

MIRANDA, J. Q.; SANTOS JUNIOR, C. D.; DIAS, A. T.. A influência das variáveis ambientais e organizacionais no desempenho de startups. Revista de Empreendedorismo e Gestão de Pequenas Empresas, v.5, n.1, 2016. 
Ainda que muitas startups tenham se destacado, no que diz respeito à inovação e aos retornos financeiros gerados, tais como o Facebook e o Uber, enfrentam dificuldades similares às de outros empreendimentos com modelos de negócios mais tradicionais. Conforme Stinchcombe (1965), as novas organizações possuem uma vulnerabilidade inicial que as tornam mais propícias aos fracassos, com maiores riscos e menores investimentos.

O fracasso é uma ameaça até mesmo para as startups que possuem os mais originais modelos de negócios, recursos adequados e empreendedores talentosos (MORRIS; SCHINDEHUTTE; ALLEN, 2005). Esta vulnerabilidade inicial deve-se ao baixo nível de legitimidade, escassez de recursos e alta dependência de cooperação, gerando uma incapacidade de competir eficazmente com as organizações já estabelecidas (STINCHCOMBE, 1965).

Por outro lado, a vulnerabilidade inicial das startups é compensada parcialmente pelo entusiasmo de seus fundadores (STRODOMSKYTE; DAI; HAUGE, 2012). Entretanto, em um cenário de longo prazo, todas precisarão construir sua legitimidade e ter acesso a recursos externos para que o empreendimento se sobressaia (STINCHCOMBE, 1965; STRODOMSKYTE; DAI; HAUGE, 2012).

Em uma pesquisa nacional, Ferreira et al. (2008) afirmam que a taxa de mortalidade de empresas de nível tecnológico é de $90 \%$ e apontam que a gestão empresarial nas incubadoras aumenta as chances de sucesso das startups, indicando assim, modelos de gestão importantes para essas empresas.

Diante disso, torna-se relevante a tentativa de analisar as diversas variáveis que influenciam o desempenho das startups com o intuito de compreender o sucesso ou fracasso da organização, sob a perspectiva estabelecida neste estudo.

O Modelo das Cinco Forças, proposto por Porter (1980), é um dos orientadores de muitas organizações para a análise do setor e das variáveis que impactam na atratividade, bem como para a estruturação da estratégia de atuação do negócio e alavancagem do desempenho. Em contrapartida, a Visão Baseada em Recursos, proposta por Barney (1991), analisa a influência dos recursos da firma e a forma de promover uma vantagem competitiva com esses recursos, sendo condicionante para o alcance do desempenho da organização. 
Nessa linha, as variáveis que influenciam o desempenho podem ser tanto ambientais (ALDRICH; PFEFFER, 1976; PORTER, 1980), quanto organizacionais (BARNEY, 1991). A partir desta perspectiva, o objetivo deste artigo é analisar a relação entre as variáveis ambientais e organizacionais no desempenho de startups.

Entender determinadas variáveis que influenciam no desempenho organizacional também contribui para a Teoria Contingencial, a saber: (i) atratividade; (ii) incerteza ambiental; (iii) estrutura organizacional; (iv) processo decisório; e (v) experiência. Todas essas variáveis estabelecem uma relação de efeito no desempenho organizacional, através de oportunidades ou restrições geradas.

\section{Empresas nascentes de base tecnológica - Startups}

O termo startup tem sido usado de maneira ampla, porém não muito clara, em diversos contextos. Brigidi (2009) afirma que mesmo em publicações especializadas no tema, como no Journal Business Venturing, não é possível encontrar uma clara definição do conceito de startup. Contudo, a FINEP (2014) apresenta um entendimento sobre o termo ao utilizar a seguinte definição:

\footnotetext{
Empresa cuja estratégia empresarial e de negócios é sustentada pela inovação e cuja base técnica de produção está sujeita a mudanças frequentes, advindas da concorrência centrada em esforços continuados de pesquisa e desenvolvimento tecnológico. Principais características das empresas nascentes de base tecnológica:

- Em estruturação empresarial (quase-empresa);

- Sem posição definida no mercado;

- Que buscam oportunidades em nichos de mercado com produtos/serviços inovadores e de alto valor agregado. (FINEP, 2014).
}

Enquanto isso, nas análises de revistas e blogs especializados (FORBES, 2013; SEBRAE, 2014; STARTUPI, 2014), destaca-se a definição mais comum de startup: uma organização temporária criada para desenvolver um modelo de negócio escalável e reproduzível em condições de extrema incerteza. Tal definição é oriunda do livro The Startup Owner's Manual (BLANK; DORF, 2014), e pode-se considerá-la vaga, pois visto que se adequa às mais diversas organizações, independente da base de inovação.

MIRANDA, J. Q.; SANTOS JUNIOR, C. D.; DIAS, A. T. A influência das variáveis ambientais e organizacionais no desempenho de startups. Revista de Empreendedorismo e Gestão de Pequenas Empresas, v.5, n.1, 2016. 
wherege

\section{Desempenho Organizacional}

O desempenho organizacional é uma forma de acompanhar o alcance do sucesso das empresas. Normalmente é analisado em função da eficiência, eficácia e efetividade da organização (SINK; TUTTLE, 1993), ou seja, pode ser observado e monitorado de várias formas, incluindo aspectos financeiros, de imagem ou de satisfação do cliente, por exemplo. Diz-se comumente que para alcançar o desempenho organizacional desejado, é relevante a construção de um conjunto de objetivos e políticas organizacionais, alinhadas com a estratégia do negócio, derivadas das oportunidades e ameaças detectadas no mercado (PORTER, 1991).

$O$ desempenho organizacional baseia-se em indicadores que mensuram 0 alcance do sucesso organizacional por meio de ações de melhoria contínua, princípios de planejamento e execução (BANKER; POTTER; SRINIVASAN, 2000; DRAGHICl; POPESCU; GOGAN, 2014; MELNYKA et al., 2014; PORTER, 1991). Essas ações internas, em geral, partem de diversas análises do contexto ambiental, bem como do contexto interno.

Diante disso, o monitoramento do desempenho organizacional via indicadores deve contemplar diferentes dimensões da organização, abrangendo a análise de indicadores financeiros (e.g., vendas) e não-financeiros (e.g., satisfação dos clientes) (DRAGHICl; POPESCU; GOGAN, 2014). Desse modo, a análise desses dois tipos de indicadores mostra-se mais adequada para as tomadas de decisões estratégicas, uma vez que traze resultados relacionados ao ambiente externo associados ao ambiente interno (BANKER; POTTER; SRINIVASAN, 2000; KENNERLY, NEELY, 2002).

\section{Desempenho de Startups}

Ao considerar uma startup como organização temporária, desenhada para criar uma solução inovadora de um problema para um conjunto de pessoas (BLANK; 
DORF, 2014), os indicadores estarão relacionados muito mais com o alcance dos objetivos sobre o produto e seu mercado do que com os resultados financeiros em si (RIES, 2011). Contudo, para a mensuração do desempenho de uma startup, são utilizados indicadores financeiros e não-financeiros, tais como: retorno sobre o investimento, sobre os ativos e sobre o patrimônio líquido (READ; SONG; SMIT, 2009); taxa de crescimento de vendas e da receita (READ; SONG; SMIT, 2009); e taxa de crescimento da empresa (HMIELESKI; ENSLEY, 2007; HMIELESKI; BARON, 2008).

Ao considerar que as startups possuem maior incerteza do ambiente e da aceitabilidade de seus produtos e serviços, os principais indicadores não devem ser financeiros, e sim concernentes ao alcance de objetivos ou expectativas que posteriormente levarão a um desempenho financeiro (CASSAR, 2014; READ; SONG; SMIT, 2009; RIES, 2011).

Ademais, os indicadores, além de mensurarem o desempenho, também têm o papel de apoiar o empreendedor com a análise do estado mais realista do seu negócio, pois, em geral, estão apaixonados e podem não visualizar os pontos de atenção. (READ; SONG; SMIT, 2009). Dessa forma, os indicadores são fundamentais para o aprendizado e tomadas de decisão mais eficazes nas startups.

\section{Atratividade do Setor}

Para enfrentar as condições ambientais, as organizações precisam adotar posições que visam explorar novas oportunidades de mercado e comportamentos, com o objetivo de sobreviver, alcançar e sustentar a vantagem competitiva (MILES; SNOW, 1978). Dessa forma, é importante existir estratégias para enfrentar a competitividade dos mercados (PORTER, 1991).

Alguns estudos apontaram a importância de considerar as contingências ambientais na modelagem das diretrizes estratégicas para aumentar o desempenho organizacional (ANSOFF, 1988; HMIELESKI; ENSLEY, 2007; MILES; SNOW, 1978; PORTER, 1980; PORTER, 1991). 
Diante disso, o Modelo das Cinco Forças contribui para um entendimento geral das forças econômicas que moldam as condições ambientais de um determinado setor industrial. Em detalhe, as Cinco Forças (PORTER, 1980) são:

1. Ameaça de novos entrantes - refere-se ao grau de competitividade do mercado, ou seja, quanto as empresas são capazes de entrar no mercado e concorrer pelos clientes;

2. Poder de negociação dos fornecedores - quando existem fornecedores com alto poder de negociação e afetam negativamente a rentabilidade de um dado setor, pois podem fazer diversas imposições, tais como preço, prazo de entrega, condições de pagamentos e qualidade dos produtos;

3. Poder de negociação dos clientes - refere-se à capacidade de o cliente forçar a baixa dos preços, aumento da qualidade ou barganha de melhores condições de pagamento;

4. Ameaça de produtos ou serviços substitutos - quando produtos e serviços de empresas concorrentes aproximam-se das mesmas necessidades dos clientes em relação aos produtos oferecidos;

5. Rivalidade entre as empresas existentes - esta força é a principal determinante do quão competitivo e rentável é o setor, pois é consequência da atuação das demais forças.

Em uma análise detalhada das Cinco Forças de Porter (1980), pode-se identificar um setor de alta atratividade, quando: possui altas barreiras de entrada; baixo poder de negociação dos compradores e dos fornecedores; poucos produtos e serviços substitutos; e baixa competição (PORTER, 1991).

Na prática, a atratividade da indústria é uma importante variável para uma organização buscar sua vantagem competitiva, pois contribui para sustentar a rentabilidade diante da competição interna e externa (PORTER, 1991). Nesta perspectiva, a iniciativa de empreender, seja pela abertura de um novo negócio ou expansão do atual, deve ser iniciada com a identificação de oportunidades, seguida pela análise do setor para identificação dos riscos e retornos envolvidos.

Dessa forma, ainda que envolva riscos, as primeiras organizações (i.e., firstmover) a investir em novidades potencialmente, obterão vantagens (LIEBERMAN; 
MONTGOMERY, 1988), pois em geral são organizações que iniciam novos produtos e serviços na frente dos competidores, influenciam nos padrões e movimento dos mercados e até mesmo podem controlar os recursos e informações, dificultando a entrada de competidores, e assim, obter melhor desempenho (LIEBERMAN; MONTGOMERY, 1988).

Assim, conforme estas análises, a primeira hipótese apresentada pressupõe que: H1 - Quanto maior a atratividade do setor, maior será o desempenho organizacional da startup.

\section{Incerteza Ambiental}

As evidências empíricas têm mostrado o efeito da incerteza ambiental sobre a estratégia (ATINC; OCAL, 2014; MINTZBERG, 1979; MUELLER; MONE; BANKER, 2007). Isto significa que as práticas de gestão, a estrutura da organização e tomada de decisão são influenciadas conforme a percepção da incerteza ambiental dos líderes (ALDRICH; PFEFFER, 1976).

Para melhor análise, definiu-se incerteza ambiental como a escassez de informações sobre eventos e ações que ocorrem no ambiente de negócios (ALDRICH; PFEFFER, 1976; DUNCAN, 1972; JABNOUN; KHALIFAH; YUSUF, 2003).

Quanto aos impactos da incerteza ambiental nas organizações, Hannan e Freeman (1977) citam a seleção natural das organizações, sendo os fatores ambientais responsáveis por selecionar aquelas com características que mais se adequam ao ambiente. Diante disso, Aldrich e Pfeffer (1976) analisam e elencam os aspectos em que o ambiente afeta a organização. São eles:

a) As restrições e as contingências do ambiente devem-se à transação com o ambiente;

b) Estas contingências afetam a distribuição de poder e influenciam na organização, gerando diferenças de poder entre as áreas;

c) O poder é utilizado para determinar a estrutura social, especialmente quando há incerteza nas decisões críticas. 
Seguindo esta perspectiva, as informações do ambiente são muito importantes para a organização, pois influenciam as variáveis organizacionais 9(estrutura organizacional), tomada de decisão e experiência. Essa influência, no caso da estrutura organizacional, direciona o fluxo da informação, comunicação e tomada de decisão (CHILD, 1972; DUNCAN, 1979; MINTZBERG; 1979).

Por fim, estudos apontam que a experiência determina 0 acesso à informação do ambiente, influenciando as decisões estratégicas e, consequentemente, o desempenho (CASSAR, 2014; CHANDLER, 1996; OE; MITSUHASHI, 2013).

\section{Estrutura Organizacional}

A estrutura organizacional é uma alocação formal dos papéis, responsabilidades e mecanismos administrativos para controlar e integrar atividades internas e externas à organização (CHILD, 1972), refletindo a forma como devem ser processados os insumos organizacionais (DUNCAN, 1979).

Diversos estudos apontam a importância da estrutura e das decisões estarem estrategicamente alinhadas com o ambiente em que estão inseridas. Nesse sentido, a organização deve analisar os fatores ambientais que a cerca, para então se reestruturar (ALDRICH; PFEFFER, 1976; CHILD, 1972; DUNCAN, 1979; FREDRICKSON, 1986; MINTZBERG, 1978; THOMPSON, 1967).

Contudo, como adequar a melhor estrutura organizacional à incerteza do ambiente? Burns e Stalker (1961) apontaram que as organizações com estruturas mais orgânicas, ou seja, com mais descentralização, autonomia e controles brandos, são mais adequadas para os ambientes mais incertos, enquanto as organizações com estruturas mais mecânicas, ou seja, maior centralização, padronização e controles burocráticos, são mais adequadas para ambientes mais estáveis (BURNS; STALKER, 1961; FOO; LEE, 2002).

Portanto, para ambientes incertos a descentralização da tomada de decisão estratégica tornaria as decisões mais ágeis, pois não sobrecarregaria 0 alto comando da organização. 
Os estudos sobre estrutura organizacional (BURNS; STALKER, 1961; FOO; LEE, 2002; HULL; HAGE, 1982) referem-se, na maioria das vezes, às grandes empresas, logo há de se tomar o cuidado em não considerá-los integralmente para as estruturas de empresas iniciantes. Em uma observação rápida, pode-se perceber que as startups até mesmo não possuem uma estrutura organizacional definida, esse fato, segundo Stinchcombe (1965), reforça a vulnerabilidade inicial das novas organizações.

Em contrapartida, as empresas iniciantes que possuem um nível maior de formalização das responsabilidades dos fundadores, especialização funcional e intensidade administrativa teriam um melhor desempenho diante de outras empresas que não possuem tal formalização (SINE; MITSUHASHI; KIRSCH, 2006). Dessa forma, comprova-se que a estrutura organizacional aumenta o desempenho das empresas iniciantes, até mesmo nos ambientes mais incertos.

Em resumo, as pesquisas apontam de que forma o ambiente influencia a estrutura organizacional e a necessidade desta estrutura estar alinhada para alcançar sua eficiência (ALDRICH; PFEFFER, 1976; BURNS; STALKER 1961; CHILD, 1972; DUNCAN, 1979, FREDRICKSON, 1986; MINTZBERG, 1979; THOMPSON, 1967). Sendo assim, estabelece-se a seguinte hipótese: H2 - A relação entre estrutura organizacional e desempenho de startups é moderada pelo grau de incerteza do ambiente.

\section{Tomada de Decisão Estratégica}

Sabe-se que as organizações em geral, possuem alguns direcionadores estratégicos para conduzir seus negócios, tanto formais quanto informais (FREDRICKSON, 1984). Nesta perspectiva, inserem-se, nas tomadas de decisões estratégicas, as decisões que afetarão a estratégia da organização (VENKATRAMAN, 1989), considerando que tais decisões que comprometem recursos significativos, estabelecem precedentes e impactam em uma série de decisões menores (MINTZBERG; RAISINGHANI; THEORET, 1976).

O processo decisório nas organizações é algo muito estudado devido à forte relação com o desempenho da organização. Para Baron (2004), os empreendedores 
mais desenvolvidos cognitivamente são capazes de avaliar melhor os riscos das empresas. Já Murmann e Sardana (2013) ressaltam em seu estudo, que a distinção dos empreendedores de sucesso dos demais é precisamente a forma como ocorre a tomada de decisão. Em contrapartida, Delmar e Shane (2003) afirmam que empreendedores são bem-sucedidos não porque adotam melhores decisões, mas porque são capazes de aproveitar todas as oportunidades que identificam ou surgem em seus caminhos, reforçando a alta propensão desses para assumirem riscos (CASSAR, 2014; DELMAR; SHANE, 2003; HMIELESKI; BARON, 2008; READ; SONG; SMIT, 2009).

As startups possuem um contexto para tomada de decisão um pouco mais delicado do que as demais organizações devido à limitação de recursos, ausência de um sistema hierárquico claro e presença de inúmeras ambiguidades e incertezas. (ESCRIBÁ-ESTEVE; SÁNCHEZ-PEINADO; SÁNCHES-PEINADO, 2008; JAMES; BARNES, 2006; MUELLER; MONE; BANKER, 2007; MURMANN; SARDANA, 2013). Decisões mais racionais podem ser úteis para este contexto, visando reduzir os riscos e minimizar as incertezas (MURMANN; SARDANA, 2013; SIMON; HOUGHTON; AQUINO, 1999), utilizando-se assim, diferentes processos de tomada de decisão conforme a exigência da situação.

Um outro meio de aumentar a racionalidade nas decisões é a busca por aconselhamentos, sendo esta uma das práticas mais básicas nas tomadas de decisões, desde as grandes organizações até Pequenas e Médias Empresas (PMEs) (MINTZBERG, 1976). Em geral, considera-se que aconselhamentos podem ser benéficos para melhorar a abrangência da decisão, expondo os decisores chaves às diferentes perspectivas e interpretações.

Ainda que muito benéfico para as decisões, o processamento de informações leva tempo e retarda o processo decisório, reduzindo seu valor em ambientes dinâmicos que requerem tomadas de decisões ágeis (MURMANN; SARDANA, 2013). Contudo, parece ser benéfica a racionalidade ser definida estritamente como o uso instrumental da informação para resolver a incerteza em torno de uma decisão, tanto em ambientes de alto ou baixo dinamismo (MUELLER; MONE; BANKER, 2007). 
Para chegar às melhores decisões estratégicas, Thompson (1967) reconhece as forças-tarefas, comitês e equipes de projetos, e então, realiza seus processos de decisão envolvendo estes grupos. Para Simons, Pelled e Smith (1999), o uso de debates entre os decisores-chave contribui positivamente com o desempenho da empresa, pois utiliza-se diferentes percepções para compreender as melhores decisões.

Portanto, para o alcance de uma decisão de menor risco e que gerará maior desempenho para a organização, as decisões mais racionais e rápidas parecem ser mais adequadas para os ambientes incertos. Diversos meios podem ser usados como forma de manter as decisões mais racionais, tais como: aconselhamentos, comitês, forças-tarefas ou equipes de projetos. Logo, propõe-se a seguinte hipótese de pesquisa: H3 - A relação entre Processo Decisório e desempenho de startups é moderada pelo grau de incerteza ambiental.

\section{Experiência dos Decisores}

Nos estudos sobre desempenho de PMEs, a experiência aparece frequentemente sendo relacionada com o desempenho, dado ao fato de o líder influenciar mais diretamente as estratégias organizacionais e de haver um relacionamento mais próximo com as equipes técnicas, os parceiros e o mercado (ENTRIALGO, 2002; ESCRIBÁ-ESTEVE; SÁNCHEZ-PEINADO; SÁNCHESPEINADO, 2008; GABRIELSSON, 2007).

Empresas iniciantes, tais como startups, geralmente necessitam de novos papéis a serem desenvolvidos, pois os conhecimentos normalmente são generalizados e resultam em análises por vezes limitadas, logo a organização necessita investir em educação, aprender com outras organizações e com os próprios erros (STINCHCOMBE, 1965).

Diante disso, é importante que o empreendedor de uma startup avalie as pessoas com quem se relaciona e suas possíveis contribuições, a fim de considerálas como uma fonte de recursos para a sua organização (SARASVATHY, 2008).

Alguns pesquisadores apontam que 0 estilo de gerenciar PMEs e 0 comportamento dos gestores são determinados pelo nível de educação 
(HAMBRICK; MASON, 1984; PAPADAKIS; BARWISE, 2002). Entretanto, os resultados da pesquisa de Escribá-Esteve, Sánchez-Peinado, Sánches-Peinado (2008) não confirmaram uma relação entre o nível de educação e habilidades para gerenciar as situações complexas e, consequentemente, obter o maior desempenho da organização.

Em relação à experiência anterior em outras startups, a pesquisa de Oe e Mitsuhashi (2013) não revelou um efeito significante no desempenho. Tal resultado pode ter sido falho, pois de acordo com os autores, não houve diferenciação entre experiências de sucesso e fracasso. Já Cassar (2014) inferiu que a experiência em outras startups é significativa, porém inferior em relação à experiência no mesmo ramo industrial.

Quanto à experiência no mesmo ramo industrial, muitos estudos apresentam uma relação positiva com o desempenho de startups. Chandler (1996) aponta que empreendedores avaliam e compreendem melhor o ambiente no qual o novo negócio irá competir se já tiverem uma experiência deste setor. Oe e Mitsuhashi (2013) apontam que esta relação acelera o crescimento do negócio, pois traz informações mais relevantes e precisas sobre operações, custos, mercados e tecnologia.

Em geral, a experiência de um empreendedor contribui para o aumento da reputação da empresa e melhores posições entre os parceiros (HAYWARD et al., 2010), bem como para alianças com investidores (OE; MITSUHASHI, 2013).

Portanto, diversas pesquisas apontam que a experiência contribui no acesso à informação, que, por sua vez, influencia na percepção de oportunidades e da incerteza do ambiente e, consequentemente, nas tomadas de decisões. Logo, fortalecem a relação entre experiência, qualquer que seja, e desempenho, resultando na seguinte hipótese: H4 - A relação entre experiência dos decisores e o desempenho de startups é moderada pela incerteza ambiental.

A Figura 1 apresenta o modelo teórico por meio das relações entre as hipóteses e o desempenho organizacional de startups. 
Procedimentos Metodológicos

A presente pesquisa tem as startups como população-alvo. Os decisores, preferencialmente os fundadores, são os respondentes. Tal critério justifica-se pela necessidade de investigação dos fatores de desempenho, estruturação, decisão e experiência dos tomadores de decisão, para então, subsidiar as devidas relações analisadas neste estudo.

O instrumento utilizado na pesquisa foi o questionário (survey) com um préteste realizado em duas etapas distintas: inicialmente, dois professores doutores do PPGA/UnB revisaram o instrumento com a finalidade de identificar a coerência e coesão com os objetivos do estudo. Posteriormente, solicitou-se a três pessoas, fundadores de startups, que respondessem aos questionários. O objetivo desta etapa foi identificar a coerência do questionário com a realidade das startups e o tempo médio de respostas.

A aproximação com as startups ocorreu por meio de incubadoras das universidades, investidores-anjos, eventos sobre startups e blogs especializados no assunto. Os respondentes foram selecionados de forma não intencional, buscando um quantitativo de dados passível de ser tratado. A técnica de amostragem utilizada foi não probabilística, por conveniência (FOWLER JR., 2013).

\section{Análise dos Dados}

O modelo e suas variáveis são caracterizados pelos seguintes fatores: 1) existem variáveis latentes que serão mensuradas por escalas (variáveis observáveis), como são os casos da atratividade, incerteza ambiental, estrutura organizacional, processo decisório e experiência; 2) existe um caminho causal de dependência entre as variáveis, como é o caso das Cinco Forças de Porter, afetando a atratividade do setor e esse exercendo influência sobre o desempenho das startups, bem como das variáveis que caracterizam a experiência dos decisores; 3) as variáveis estrutura organizacional, processo decisório e experiência afetam o 
desempenho das startups e são influenciadas pelos fatores de incerteza ambiental simultaneamente.

Foi elaborado um modelo de mensuração (Figura 1), que traz a visão do modelo teórico e os procedimentos adotados na estruturação do questionário. No modelo é possível visualizar a respectiva variável que cada pergunta do questionário (anexo I) buscou identificar.

A estrutura do modelo de mensuração está ajustada conforme os constructos formativos ou reflexivos de cada variável latente, uma vez que incide na análise e na mensuração do constructo (BOLLEN; LENNOX, 1991).

$\mathrm{Na}$ análise da moderação da variável incerteza ambiental, utilizou-se a proposta de Baron e Kenny (1986), a qual conceitua a moderação como uma variável qualitativa ou quantitativa que afeta a direção e/ou a força da relação entre a variável independente (VI) e a dependente (VD).

Diante disso, identificou-se a necessidade de modelagem de equações estruturais (SEM) (CHIN, 1998; HAIR et al., 2009). A escolha de equações estruturais se justifica principalmente pelas características das hipóteses desenvolvidas, requerendo uma modelagem de equações simultaneamente.

Para a análise dos dados de rejeição ou aceitação das hipóteses, utilizou-se o software SmartPLS, que é um dos utilizados para cálculos que envolvem PLSSEM, apresentando as relações entre os constructos latentes independentes e dependentes.

Para as questões referentes à experiência, calculou-se uma média geral entre todos os decisores para obter a média da startup em cada um dos indicadores: escolaridade, experiência em gestão de startups, experiência em gestão em diferentes setores do negócio e experiência como empreendedor.

O software para os testes foram configurados com interações máximas de 300 e o stop criterion $\left(10^{\wedge}-X\right) 7$, enquanto que para a análise da significância, gerouse o Bootstrapping ${ }^{4}$ com subamostras de 5.000, no sign chances e nível de significância de 5\% (WONG, 2013).

\footnotetext{
${ }^{4}$ A técnica bootstrapping valida um modelo multivariado pela extração de um grande número de subamostras, estimando modelos para cada subamostra e então determinando o valor para as 
Ao rodar o primeiro modelo no software com todas as variáveis e indicadores, conforme o modelo de mensuração indicado na Figura 1 , os indicadores, Experiência em outros setores do negócio e Incerteza, apresentaram coeficiente igual a 1,059 e 1,002, respectivamente, ou seja, problemas de multicolinearidade ${ }^{5}$.

Dessa forma, com o objetivo de gerar análises mais consistentes, os dois indicadores foram removidos e o modelo foi ajustado. Assim, as análises foram realizadas a partir de um novo modelo, nomeado de Teste 1.

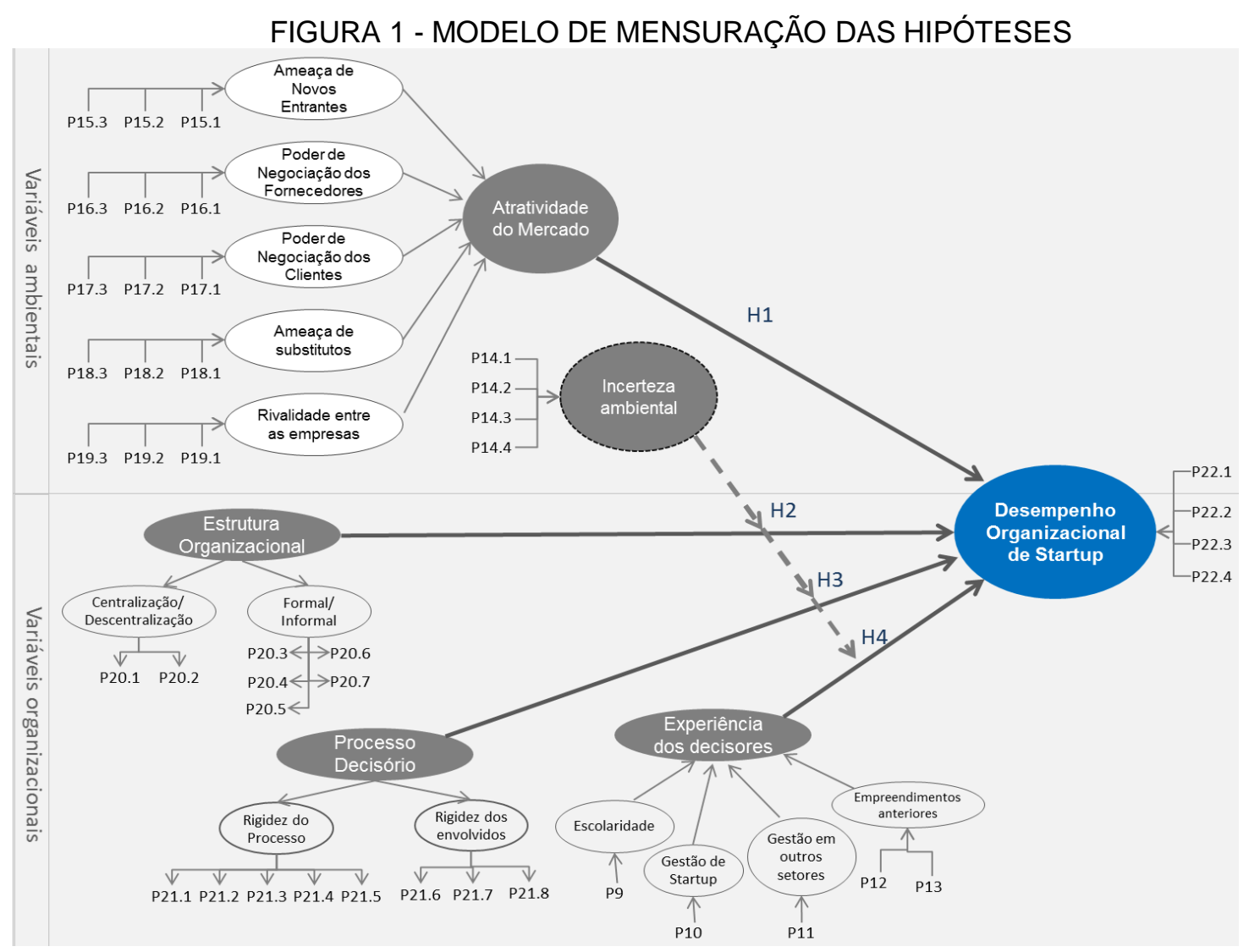

FONTE: Os autores (2016)

A partir do Teste 1, diversos outros modelos foram rodados com diferentes ajustes, no intuito de observar com maior clareza qual apresentaria significância estimado ao longo de todos os modelos de subamostras (HAIR et al.2009, p. 39).

MIRANDA, J. Q.; SANTOS JUNIOR, C. D.; DIAS, A. T. . A influência das variáveis ambientais e organizacionais no desempenho de startups. Revista de Empreendedorismo e Gestão de Pequenas Empresas, v.5, n.1, 2016. 
estatística e, ainda, a variação no $\mathrm{R}^{2}$. Os ajustes foram realizados nos indicadores de mensuração para observar quais apresentavam baixo nível de significância estatística e compreensão textual das perguntas dos questionários. A seguir, a Tabela 1 apresenta um detalhamento das variáveis e indicadores utilizados para a simulação de cada um dos testes.

${ }^{5}$ A multicolinearidade cria variância "compartilhada" entre variáveis, diminuindo a capacidade de prever a medida de dependente, bem como de investigar os papéis relativos de cada variável independente (HAIR et al., 2009). 
TABELA 1 - RELAÇÃO DAS VARIÁVEIS E INDICADORES ANALISADOS EM CADA SIMULAÇÃO DOS TESTES

$\begin{array}{cll}\text { Teste } & \text { Variáveis Independentes Indicadores utilizados }\end{array}$

Desempenho (Constructo Formativo)

P22.1; P22.2; P22.3; P22.4

Novos entrantes - P15.1; P15.2; P15.3

Teste $1 \quad$ Atratividade (Constructo Formativo)

Neg. fornecedores - P16.1; P16.2; P16.3

Neg. clientes - P17.1; P17.2; P17.3

Rodado no software exatamente como proposto

no modelo de mensuração e

as perguntas do questionário (indicadores)

Incerteza (Constructo Formativo)

Substitutos - P18.1:P18.2; P18.3

Rivalidade - P19.1; P19.2; P19.3

Experiência (Constructo Formativo) P14.1; P14.3; P14.4

Estrutura Organizacional (Constructo Reflexivo) P9; P10; P12

Processo Decisório (Constructo Reflexivo)

\section{Centralização - P20.1; P20.2}

Formalizacão - P20.3; P20.4; P20.5; P20.6; P20.7

Rigidez do Processo - P21.1; P21.2; P21.3; P21.4; P21.5 Rigidez dos Envolvidos - P21.6; P21.7; P21.8

Teste 2

A execução foi realizada com todas as nuances do Teste 1 e acrescentada a variável incerteza como moderadora das variáveis organizacionais (experiência, estrutura organizacional e tomada de decisão)

\section{Teste 3}

A partir do Teste 1, efetuouse a revisão das questões no questionário e remoção das que (indicadores) não possuíam clareza textual, dos indicadores com baixo nível de significância estatística. Adicionalmente, ao revisar as questões da variável processo decisório, identifica-se que todas se adequariam em aspectos de rigidez do processo, ligando os indicadores diretamente a esta variável.

Em tachado estão os destaques das variáveis

\section{Desempenho (Constructo Formativo)}

Atratividade (Constructo Formativo)

\section{Incerteza (Constructo Formativo)}

Experiência (Constructo Formativo)

Estrutura Organizacional (Constructo Reflexivo)

Processo Decisório (Constructo Reflexivo)

\section{P22.1; P22.2; P22.3; P22.4}

Novos entrantes - P15.1; P15.2; P15.3

Neg. fornecedores - P16.1; P16.2; P16.2

Neg. clientes - P17.1; P17.2; P17.3

Substitutos - P18.1; P18.2; P18.3

Rivalidade - P19.1; P19.2; P19.3

P14.1; P14.2; P14.3; P14.4

P9; P10; P12

Centralização - P20.1; P20.2

Formalização - P20.3; P20.4; P20.5; P20.6; P20.7

Rigidez do Processo- P21.1; P21.2; P21.3; P21.4; P21.5

Rigidez dos Envolvidos- P21.6; P21.7; P21.8

MIRANDA, J. Q.; SANTOS JUNIOR, C. D.; DIAS, A. T.. A influência das variáveis ambientais e organizacionais no desempenho de startups. Revista de Empreendedorismo e Gestão de Pequenas Empresas, v.5, n.1, 2016. 


\begin{tabular}{|c|c|c|}
\hline Teste & Variáveis Independentes & Indicadores utilizados \\
\hline \multicolumn{3}{|l|}{$\begin{array}{l}\text { removidas em relação ao } \\
\text { Teste } 1\end{array}$} \\
\hline Teste 4 & \multicolumn{2}{|c|}{$\begin{array}{l}\text { A execução foi realizada com todas as nuances do Teste } 3 \text {, acrescentando-se a variável incerteza como } \\
\text { moderadora das variáveis organizacionais (experiência, estrutura organizacional e tomada de decisão) }\end{array}$} \\
\hline \multirow{6}{*}{$\begin{array}{c}\text { Teste } 5 \\
\text { A partir do Teste 3, efetuou- } \\
\text { se a revisão das questões no } \\
\text { questionário e foram } \\
\text { removidos os indicadores } \\
\text { com baixo nível de } \\
\text { significância estatística. } \\
\text { Adicionalmente, ao revisar as } \\
\text { questões da atratividade, } \\
\text { realizou-se ajustes visando } \\
\text { simplificar a mensuração, } \\
\text { assim, os indicadores formam } \\
\text { diretamente a variável } \\
\text { atratividade. }\end{array}$} & Desempenho (Constructo Formativo) & P22.1; P22.2; P22.3; P22.4 \\
\hline & Atratividade (Constructo Formativo & $\begin{array}{l}\text { Novos entrantes P15.1; P15.2; P15.3 } \\
\text { Neg. fornecedores P16.1; P16.2; P16.2 } \\
\text { Neg. clientes P17.1; P17.2; P17.3 } \\
\text { Substitutos P18.1; P18.2; P18.3 } \\
\text { Rivalidade P19.1; P19.2;P19.3 }\end{array}$ \\
\hline & Incerteza (Constructo Formativo) & P14.1; P14.2; P14.3; P14.4 \\
\hline & Experiência (Constructo Formativo) & P9; P10; P12 \\
\hline & Estrutura Organizacional (Constructo Reflexivo) & $\begin{array}{l}\text { Centralização - P20.1; P20.2 } \\
\text { Formalização - P20.3; P20.4; P20.5; P20.6; P20.7 }\end{array}$ \\
\hline & Processo Decisório (Constructo Reflexivo) & $\begin{array}{l}\text { Rigidez do Processo-P21.1; P21.2; P21.3; P21.4; P21.5 } \\
\text { Rigidez dos Envolvidos- } \quad \text { P21.6; P21.7; P21.8 }\end{array}$ \\
\hline $\begin{array}{c}\text { Em-tachado estão os } \\
\text { destaques das variáveis } \\
\text { removidas em relação ao } \\
\text { Teste } 1\end{array}$ & & \\
\hline Teste 6 & \multicolumn{2}{|c|}{$\begin{array}{l}\text { A execução foi realizada com todas as nuances do Teste } 5 \text {, acrescentando-se a variável incerteza como } \\
\text { moderadora das variáveis organizacionais (experiência, estrutura organizacional e tomada de decisão) }\end{array}$} \\
\hline
\end{tabular}

FONTE: Autores (2016) moderadora das variáveis organizacionais (experiência, estrutura organizacional e tomada de decisão)

MIRANDA, J. Q.; SANTOS JUNIOR, C. D.; DIAS, A. T.. A influência das variáveis ambientais e organizacionais no desempenho de startups. Revista de Empreendedorismo e Gestão de Pequenas Empresas, v.5, n.1, 2016. 


\section{Resultados dos testes de hipótese}

Ao todo, houve 128 respondentes, dos quais apenas 102 responderam completamente o questionário e, dentre os 102 respondentes, 92 caracterizaram-se como startups.

O questionário foi enviado para startups de todo o Brasil, mas a maioria dos respondentes localizava-se em Brasília, representando 23\%, seguido de Minas Gerais, com 22\%, e Rio de Janeiro, com 18\%. A maior participação em Brasília pode estar vinculada ao relacionamento mais próximo dos pesquisadores com os fundadores.

Em relação à quantidade de fundadores nas startups, grande parte possui 2 fundadores (37\%), seguido de apenas 1 fundador (25\%). Quanto à presença de cofundadores, a maioria da amostra possui 2 (38\%), seguido de ausência de cofundadores (23\%).

Quanto à característica Setor do Negócio, os respondentes poderiam escolher um setor ou detalhar a informação no campo Outros. Como consequência, houve uma extensa lista de setores indicados. Para garantir melhor acuracidade, analisou-se detalhadamente a empresa respondente e então, houve nova caracterização de acordo com o setor principal de atuação da empresa.

Diante disso, os setores que se destacam são: (i) telecomunicações e informática, com 33\%; e (ii) educação, com 12\%. Interessante notar que estas empresas referentes ao setor de educação possuem propostas inovadoras de educação e geração de conhecimento e têm se tornado popular para muitos consumidores que buscam conhecimento de uma maneira diferenciada da forma tradicional.

Para a característica relacionada aos tipos de investimentos, os respondentes apontaram um ou dois tipos de investimentos. Para facilitar a análise, distribuiu-se os pesos proporcionalmente para as variações de investimento de cada resposta. Sendo que nos casos de apenas um tipo de investimento, contabilizou-se o peso único $(1,0)$, enquanto para as startups que apontaram dois tipos de investimentos, contabilizou-se o peso distribuído $(0,5)$ para cada investimento. 
Feito o cálculo, percebeu-se que o investimento pessoal ou familiar é o mais comum diante dos outros investimentos, representando $58 \%$, ou seja, 53 startups apresentaram este tipo de investimento. Os números são: 13\% para empréstimos públicos, $10 \%$ para empréstimos privados e $8 \%$ para nenhum tipo de investimento. Diante disso, identificou-se que a maioria das startups não possui acesso a outros investimentos além do pessoal.

Em relação à idade das startups da amostra, 33\% possuem entre 1 a 2 anos, 23\% estão acima de 3 anos e 20\% possuem entre 2 a 3 anos de funcionamento. Com relação à quantidade de colaboradores, excetuando-se os decisores, 64\% das startups possuem entre 1 a 10 colaboradores e $28 \%$ não possuem nenhum colaborador além dos decisores. Portanto, observa-se que, ainda que a maioria das startups possuam acima de 1 ano de funcionamento, elas não contam com elevada quantidade de colaboradores.

Quanto aos participantes das decisões estratégicas nestas startups, 43\% apontam que os participantes das decisões são somente os fundadores, seguido de $20 \%$ em que todos os colaboradores participam das decisões.

Maiores detalhes da amostra pode ser observado na Tabela 2, a qual apresenta as distribuições gerais da amostra, considerando as características levantadas entre os respondentes. 


\section{Amostra Total}

92 Startups

\begin{tabular}{|c|c|c|c|c|c|}
\hline Característica & Qtde. & Perc. & Característica & Qtde. & Perc \\
\hline Localização de Origem & & & Tipos de Investimentos & & \\
\hline DF & 21 & $23 \%$ & $\begin{array}{l}\text { Investimentos pessoais ou } \\
\text { familiares }\end{array}$ & 53 & $58 \%$ \\
\hline$M G$ & 20 & $22 \%$ & $\begin{array}{l}\text { Empréstimos Públicos (Ex: } \\
\text { subvenções, editais e bolsas) }\end{array}$ & 12 & $13 \%$ \\
\hline RJ & 17 & $18 \%$ & Empréstimos Privados & 9 & $10 \%$ \\
\hline SP & 15 & $16 \%$ & Sem investimentos & 7,5 & $8 \%$ \\
\hline Outros & 19 & $21 \%$ & Investimento Anjo & 6 & $7 \%$ \\
\hline $\begin{array}{l}\text { Quantidade de } \\
\text { Fundadores em cada } \\
\text { startup }\end{array}$ & & & Outros & 4,5 & $5 \%$ \\
\hline Apenas 1 & 25 & $27 \%$ & Idade da Startup & & \\
\hline Há 2 & 34 & $37 \%$ & Menos de 6 meses & 10 & $11 \%$ \\
\hline Há 3 & 18 & $20 \%$ & Entre 6 meses a 1 ano & 13 & $14 \%$ \\
\hline Há 4 & 9 & $10 \%$ & Entre 1 ano a 2 anos & 30 & $33 \%$ \\
\hline \multirow[t]{2}{*}{ Há 5 ou mais } & 6 & $7 \%$ & Entre 2 anos a 3 anos & 18 & $20 \%$ \\
\hline & & & Acima de 3 anos & 21 & $23 \%$ \\
\hline Quantos Co-fundadores & & & Quantos colaboradores & & \\
\hline Não há & 21 & $23 \%$ & Nenhum colaborador & 26 & $28 \%$ \\
\hline Apenas 1 & 17 & $18 \%$ & Entre 1 a 10 & 59 & $64 \%$ \\
\hline Há 2 & 35 & $38 \%$ & Entre 11 a 20 & 3 & $3 \%$ \\
\hline Há 3 & 10 & $11 \%$ & Entre 20 a 30 & 2 & $2 \%$ \\
\hline Há 4 ou mais & 9 & $10 \%$ & Entre 50 a 100 & 1 & $1 \%$ \\
\hline \multicolumn{6}{|l|}{ Setores das Startups } \\
\hline $\begin{array}{l}\text { Telecomunicaçõe e } \\
\text { Informática }\end{array}$ & 30 & $33 \%$ & $\begin{array}{l}\text { Participam das Tomadas de } \\
\text { Decisões }\end{array}$ & & \\
\hline Educação e Cultura & 11 & $12 \%$ & Todos os fundadores & 40 & $43 \%$ \\
\hline Softwares e games & 8 & $9 \%$ & Todos & 18 & $20 \%$ \\
\hline Comunicação & 7 & $8 \%$ & Todos co-fundadores & 8 & $9 \%$ \\
\hline \multirow[t]{2}{*}{ Outros } & 36 & $39 \%$ & Alguns co-fundadores & 4 & $4 \%$ \\
\hline & & & Colaboradores & 3 & $3 \%$ \\
\hline
\end{tabular}

FONTE: Autores (2016). 


\section{Resultados do teste de hipóteses}

Nos diversos testes realizados, os coeficientes de correlação das variáveis independentes apresentaram força para prever a variável dependente do desempenho. Nas hipóteses $\mathrm{H} 1$ e H2, os coeficientes apresentaram correlação positiva, enquanto que nas $\mathrm{H} 3$ e H4, constatou-se correlação negativa.

Já o $\mathrm{R}^{2}$, que apresenta a força na relação entre as variáveis indepententes e a variável dependente, identifica-se um aumento incremental do valor a partir da inserção da incerteza como uma variável moderadora das variáveis independentes organizacionais. A diferença do $R^{2}$ entre os testes T2 e T1 $(0,361-0241=0,12)$ é de $12 \%$, ou seja, este valor representa o aumento da capacidade de prever a variável dependente quando há a presença da incerteza ambiental como moderadora das variáveis organizacionais.

\section{Atratividade do Setor}

Nos resultados estatísticos do teste de hipóteses, apresentados na Tabela 3, observou-se que a atratividade do setor, em geral, mantém uma correlação positiva com o desempenho de startups, conforme proposto na hipótese $\mathbf{H 1}$, apesar de que em nenhum dos testes ficou evidenciada significância estatística nesta relação. Diante disso, esta hipótese $\mathrm{H} 1$ é rejeitada, pois não é possível determinar a presença da relação entre as variáveis.

Contudo, ao analisar detalhadamente os resultados estatísticos e o questionário, obtêm-se algumas nuances desta variável. Pode-se destacar que os clientes das startups participantes possuem alto poder de negociação e que os produtos substitutos podem afetar o seu negócio.

Esse resultado é curioso ao considerar que, em geral, as startups oferecem um produto ou serviço inovador não existente no mercado. O cliente é sempre o foco central na essência do negócio das startups e o sucesso é a consequência de como o produto foi recebido pelos seus clientes. Neste ponto, é importante ressaltar que 
caso o produto não seja aceitável, a startup precisará rever todo o seu negócio e adequar-se para atendê-los de forma satisfatória.

Em relação aos produtos substitutos serem considerados uma ameaça ao negócio, é preciso lembrar que mesmo que seus produtos sejam inovadores, eles podem ser facilmente imitados e replicados pelos concorrentes, afetando, consequentemente, a atratividade e a rentabilidade do negócio.

Diante disso, a origem das startups, em geral, remete à combinação de diversos tipos de negócio ou uma "dor" identificada no mercado. Caso as startups foquem o seu modelo de negócio em um mercado específico, comum às startups, elas passarão por desvantagens, caso haja alterações no segmento focado.

\section{Incerteza}

A variável incerteza ambiental, conforme observado na Tabela 3 , ao atuar somente como uma variável independente, como nos testes T1, T3 e T5, não apresentou força para influenciar no desempenho. Contudo, como uma variável moderadora das variáveis organizacionais nos testes T2, T4 e T6, a incerteza ambiental implicou em alterações nas correlações das variáveis independentes com a desempenho.

Quanto às variáveis independentes, relacionadas diretamente com 0 desempenho, sem a moderação, notou-se uma redução de suas correlações, enquanto que, com moderação (hipóteses H3 e H4), foi aumentada sua capacidade de influenciar no desempenho. A exceção foi a estrutura organizacional $(\mathrm{H} 2)$, que em todos os testes observou-se uma correlação mais forte com o desempenho, quando não há a presença da moderação.

O aumento moderado do $\mathrm{R}^{2}$ no teste de hipótese na presença da incerteza, leva a identificar esta variável como relevante para compreender as influências no desempenho. Como as teorias relacionadas à incerteza ambiental, esta é uma característica relevante para a análise, pois influencia na estratégia organizacional das empresas.

Como já previsto anteriormente, identificou-se uma elevada presença da incerteza no contexto das startups, tanto nas questões relacionadas diretamente 
com a incerteza, quanto nas questões que solicitavam a descrição das razões que as consideravam startups.

\section{Estrutura Organizacional}

A estrutura organizacional, conforme observado na Tabela 3, mantém uma correlação positiva com o desempenho de startups em sua influência direta e apresentou significância estatística no teste 3, cuja mensuração foi realizada por indicadores que identificavam níveis de centralização e formalização da estrutura organizacional das startups.

Contudo, nos demais testes, a variável estrutura organizacional sob a moderação da incerteza ambiental, conforme proposto na hipótese $\mathrm{H} 2$, apresenta uma correlação positiva no teste T2 e nos demais, uma baixíssima correlação (T4 e T“6). Adicionalmente, não apresentou significância estatística em nenhum dos testes. Diante disso, esta hipótese H2 é rejeitada, pois não é possível determinar a presença da relação entre as variáveis.

Com o objetivo de melhor compreender o contexto de estrutura organizacional das startups, analisou-se as respostas dos questionários, identificando que grande parte das startups participantes do estudo tem um nível moderado de formalização e centralização em sua estrutura organizacional. Em vista disso, ainda que o contexto de incerteza ambiental seja elevado entre as startups, estas organizações já apresentam níveis de formalização em sua estrutura organizacional, e tais níveis de organização influenciam no seu desempenho.

Diante desses resultados, identifica-se que a análise da estrutura organizacional de forma tradicional, como é avaliada em organizações mais estabelecidas, pode não ser adequada para avaliar estruturas de startups. As startups possuem um modelo de negócio de base tecnológica com características organizacionais e estratégicas diferentes das tradicionais, necessitando de estudos diferenciados. 


\section{Tomada de Decisão Estratégica}

Nos resultados estatísticos, conforme observado na Tabela 3, identificou-se que a variável tomada de decisão apresentou correlação positiva com o desempenho de startups em sua influência direta e significância estatística nos testes T3 a T6. Na presença da moderação da incerteza, conforme proposto na hipótese $\mathrm{H} 3$, a tomada de decisão apresentou correlação negativa.

Considerando a análise crua do coeficiente de correlação negativo de $\mathrm{H} 3$, é possível identificar que, sob condição de incerteza, toda rigidez do processo para reduzir a incerteza pode não influenciar no desempenho das startups. No entanto, não foi identificada significância estatística. Diante disso, esta hipótese H3 é rejeitada, pois não foi possível determinar a presença da relação entre as variáveis.

Para compreender melhor o processo de tomada de decisão nas startups, analisou-se o questionário de coleta de dados. A tomada de decisão foi mensurada por indicadores relacionados à rigidez do processo. Observou-se que, comumente, as startups realizam tomadas de decisões mais rígidas com o objetivo de reduzir a incerteza na tomada de decisão. Em geral, as decisões são baseadas em análise de cenários, busca de vantagem competitiva e utilização dos colaboradores como fontes de informações.

Notou-se, portanto, que as startups utilizam de algumas premissas nas tomadas de decisão estratégica para reduzir a incerteza inerente ao seu contexto, mas não foi possível estabelecer relação com o desempenho.

\section{Experiência}

Nos resultados estatísticos do teste de hipóteses, conforme observado na Tabela 3, a variável experiência dos decisores correlaciona-se negativamente com o desempenho quando possui sua influencia direta (T1, T2 e T5). Na presença da variável moderadora incerteza ambiental, conforme proposto na hipótese $\mathrm{H4}$, a correlação negativa passa a ser ainda maior com o desempenho. Isto significa que 
quanto maior a incerteza ambiental, menos a experiência tem efeito no desempenho.

$\mathrm{Na}$ prática, para as startups, os resultados do coeficiente significam que se elas estão sob uma percepção de incerteza muito grande para as tomadas de decisões, a experiência dos decisores não influencia nas decisões e, consequentemente, não terá efeito no desempenho alcançado pela startup.

Contudo, a experiência dos decisores não apresentou significância estatística. Diante disso, esta hipótese H4 é rejeitada, pois não foi possível determinar a presença da relação entre as variáveis.

Para ajudar na compreensão da experiência da amostra, analisou-se em detalhe os dados: (i) Escolaridade - 82\% dos decisores possuem mais que o Ensino Superior Completo; (ii) Experiência em gestão de startups - 92\% deles possuem menos que 3 anos; (iii) Experiência em outros setores diferente da startup - 65\% possuem menos que 3 anos; (iv) Experiência prévia como empreendedor - 80\% possuem menos que 3 anos de experiência como empreendedor.

Ainda, a maioria das startups do estudo possui um ou dois fundadores e nenhum ou dois co-fundadores, ou seja, em uma soma de experiências, a baixa quantidade de decisores acaba por influenciar na experiência geral da organização.

Diante destes dados, o desempenho das startups analisadas pode não estar de fato sendo influenciado pela experiência, já que a experiência média é baixa, não sendo possível, portanto, constatar tal relação.

\section{Modelo Teórico Exploratório}

Com o objetivo de desenvolver o conhecimento relacionado às startups, estruturou-se uma visão diferenciada do modelo teórico inicial a partir dos dados coletados.

A presença da incerteza como uma variável moderadora aumenta o coeficiente de determinação da variável dependente $\left(R^{2}\right)$. Adicionalmente, é uma variável muito presente no contexto das startups e, por consequência, é abordada intuitivamente em todo o comportamento dos empreendedores, principalmente na incerteza relacionada ao próprio modelo de negócio. 
Diante disso, pode-se observar a presença da incerteza ambiental também na análise da atratividade do mercado, pois há produtos e serviços que ainda não conseguiram identificar com clareza quais são seus concorrentes ou quais não possuem informações para tal análise, fato comum principalmente para as startups que encontram-se em fase de desenvolvimeto da ideia. Dessa forma, tem-se uma nova hipótese: H1b - A relação entre atratividade do setor e desempenho de startups é moderada pelo grau de incerteza ambiental.

Observou-se que a atratividade iria perdendo força de acordo com os ajustes dos indicadores. Diante deste cenário, uma mensuração em que todos os indicadores estavam conectados diretamente com a atratividade, sem a presença das cinco forças como $2^{\mathrm{a}}$ ordem, pode-se perceber um aumento do $\mathrm{R}^{2}$ desta variável e, consequentemente, do desempenho.

Em relação aos testes do modelo teórico, notou-se um aumento nas correlações das variáveis com a Vmod incerteza no modelo exploratório.

Em resumo, todas as variáveis são moderadas pela incerteza, de forma que se apresentou um maior poder explicativo do desempenho, tendo uma alteração do $\mathrm{R}^{2}$ de 0,361 (T2) para 0,541 no novo modelo teórico exploratório, ou seja, aumento de $18 \%$ no poder de explicação do desempenho.

Em detalhe, as variações de todos os testes e do modelo exploratório podem ser visualizadas na Tabela 3. 
TABELA 3 - TABELA COMPARATIVA COM OS RESULTADOS DE TODOS OS TESTES E DO MODELO EXPLORATÓRIO

\section{Análises via SmartPLS}

\begin{tabular}{|c|c|c|c|c|c|c|c|}
\hline \multicolumn{8}{|c|}{ Análises via SmartPLS } \\
\hline & $\begin{array}{c}\mathrm{T} 1 \\
\mathrm{R}^{2}- \\
0,241\end{array}$ & $\begin{array}{c}\text { T2 } \\
\text { T1 com } \\
\text { moderaçã } \\
0 \\
\mathrm{R}^{2}-0,361\end{array}$ & $\begin{array}{c}\text { T3 } \\
R^{2}- \\
0,231\end{array}$ & $\begin{array}{c}\text { T4 } \\
\text { T3 com } \\
\text { moderação } \\
\mathrm{R}^{2}-0,322\end{array}$ & $\begin{array}{c}\text { T5 } \\
R^{2}- \\
0,210\end{array}$ & $\begin{array}{c}\mathrm{T} 6 \\
\text { T5 com } \\
\text { moderaçã } \\
0 \\
\mathrm{R}^{2}-0,250\end{array}$ & $\begin{array}{c}\text { Modelo } \\
\text { Exploratóri } \\
0 \\
\mathrm{R}^{2}-0,541\end{array}$ \\
\hline Desempenho & - & - & - & - & - & - & - \\
\hline $\begin{array}{l}\text { Estrutura } \\
\text { Organizaciona } \\
\text { I }\end{array}$ & 0,249 & 0,185 & $0,264^{*}$ & 0,218 & 0,213 & 0,167 & 0,016 \\
\hline $\begin{array}{l}\text { Processo } \\
\text { Decisório }\end{array}$ & 0,194 & 0,163 & $0,219^{\star}$ & $0,230^{*}$ & $0,228^{*}$ & $0,262^{*}$ & 0,181 \\
\hline Experiência & $-0,120$ & 0,015 & $-0,162$ & 0,007 & $-0,190$ & $-0,078$ & 0,074 \\
\hline Incerteza & 0,055 & 0,107 & 0,083 & 0,020 & $-0,103$ & $-0,040$ & 0,084 \\
\hline $\begin{array}{l}\mathrm{H} 1 \text { - } \\
\text { Atratividade }\end{array}$ & 0,192 & 0,140 & 0,090 & 0,079 & 0,119 & 0,088 & - \\
\hline $\begin{array}{l}\mathrm{H} 2 \text { - } \\
\text { Incerteza* } \\
\text { Estrutura } \\
\text { Organizaciona } \\
\text { I }\end{array}$ & - & 0,148 & - & 0,092 & - & $-0,051$ & $-0,048$ \\
\hline $\begin{array}{l}\text { H3 - } \\
\text { Incerteza*Proc } \\
\text { esso Decisório }\end{array}$ & - & $-1,99$ & - & $-0,148$ & - & $-0,150$ & $-0,264$ \\
\hline $\begin{array}{l}\mathrm{H} 4 \text { - } \\
\text { Incerteza* }^{*} \\
\text { Experiência }\end{array}$ & - & $-0,179$ & - & 0,207 & - & 0,112 & $-0,130$ \\
\hline $\begin{array}{l}\mathrm{H} 1 \mathrm{~b}- \\
\text { Incerteza* }^{*} \\
\text { Atratividade }\end{array}$ & - & - & - & - & - & - & -0358 \\
\hline${ }^{*} \mathrm{~T}$ statisttic $\mathrm{m}$ & nor que 0 , & & & & & & \\
\hline
\end{tabular}

\section{Discussão dos Resultados}

Pode-se observar nas análises dos resultados, como apresentado na seção anterior, que as hipóteses analisadas neste estudo não apresentaram significância estatística. Diante dos resultados, assume-se que as relações estabelecidas não influenciam no desempenho das startups. Em relação à teoria, estes resultados eram inesperados, contudo, existem estudos anteriores que também apresentaram 
resultados similares a este. Um fator a ser considerado nos resultados pode ser o contexto específico das startups.

As startups iniciam e desenvolvem seus negócios com algumas características diferentes das demais organizações, e é importante conhecê-las para compreender melhor os resultados apresentados. Blank e Dorf (2014) discutem algumas das principais diferenças:

a) Há uma orientação pela tecnologia e um potencial muito grande de crescimento;

b) Devido à inovação tecnológica do seu produto ou serviço, possuem uma elevada incerteza quanto ao sucesso de sua oferta no mercado. Dessa forma, lidam constantemente com ajustes de sua oferta;

c) A relação de investimento é diferente, pois procuram investimentos via investidores-anjos ou empresas de capital de risco, as quais têm um papel de investir em empresas com maiores chances de retorno e um menor risco, e ainda, terão um papel ativo no desenvolvimento da startup;

d) Caso os fundadores da ideia da startup não se considerem experientes o suficiente, podem recorrer às incubadoras ou aceleradoras para obter ajuda para estruturar o modelo de negócio e a estratégia a ser utilizada.

Dito isto, poucas pesquisas relacionadas ao desempenho de startups analisam a variável atratividade, porém, em diversas pesquisas sobre grandes organizações, a atratividade apresenta-se como influenciadora do desempenho. Stuart e Abetti (1987) analisaram que a atratividade está entre um dos fatores que apresentaram impactos negativos no sucesso de novos empreendimentos, o que não era esperado pelos pesquisadores.

Dessa forma, podem existir diversas explicações para o resultado sobre atratividade. Inicialmente, a análise da atratividade pode ter vícios, pois os fundadores do negócio tornam-se tão apaixonados pela ideia, que são suficientemente convencidos da alta atratividade de seu mercado (CHANDLER; HANKS, 1994). Ou ainda, algumas startups não conseguem identificar com maior clareza seus clientes e competidores (ROCHA, 2008; MINATOGAWA, 2013).

Quanto à estrutura organizacional, observou-se que as startups já apresentam níveis de formalização em sua estrutura organizacional e tais níveis de 
organização influenciam no seu desempenho. Os dados corroboram com os resultados da pesquisa de Sine, Mitsuhashi, Kirsch (2006), os quais apontam que empresas iniciantes que possuem um nível maior de formalização das responsabilidades e especialização funcional teriam um maior desempenho diante de outras empresas que não possuiriam tal formalização.

Já com relação à variável tomada de decisão estratégica, identificou-se que as startups possuem processos para as análises, como forma de minimizar as incertezas inerentes ao contexto. Consequentemente, torna-se maior a busca por informações para tomadas de decisões, conforme apontado por diversos autores (ESCRIBÁ-ESTEVE; SÁNCHEZ-PEINADO; SÁNCHES-PEINADO, 2008; JAMES; BARNES, 2006; MUELLER; MONE; BANKER, 2007; MURMANN; SARDANA, 2013).

Em relação à experiência dos decisores, compreende-se que não ter encontrado significância na relação com o desempenho é um fato surpreendente para os pesquisadores de empreendedorismo (ENTRIALGO, 2002; GABRIELSSON, 2007; PAPADAKIS; BARWISE, 2002; SARASVATHY, 2008). É preciso salientar que algumas pesquisas já apontaram a ausência da relação entre experiência e desempenho. A exemplo de Escribá-Esteve, Sánchez-Peinado e Sánches-Peinado (2008), que não confirmaram uma relação entre o nível de educação e habilidades para gerenciar as situações complexas e maior desempenho da organização. A pesquisa de Oe e Mitsuhashi (2013) não revelou um efeito significante com desempenho, resultado que pode ter sido falho, pois, segundo os autores, não houve a diferenciação entre experiências de sucesso e as de fracasso.

Há a possibilidade, ainda, desta pesquisa ter enfrentado um dos problemas de amostra indicados por Hair et al., (2009). De acordo com o autor, amostras pequenas podem resultar em baixíssimo poder estatístico para identificar resultados significantes. Contudo, compreende-se que os resultados podem, de fato, estar relacionados à ausência de influência e ainda, trazer alguns insights sobre as variáveis. 


\section{Considerações Finais}

As startups são organizações com negócios focados em grandes mercados e de crescimento rápido, caracterizadas por um perfil mais dinâmico e inovador em relação aos outros modelos. Elas possuem diversas características de organização e formalização das responsabilidades de seus colaboradores e fundadores, sendo a incerteza uma variável predominante e já incorporada em sua organização interna e na dinâmica de tomada de decisão.

A variável experiência foi baixa no grupo amostral, mas o coeficiente levanos à refletir que pode não exercer influência em condições de elevada incerteza ambiental. Adicionalmente, identifica-se que há diversos fatores para avaliar a experiência e analisar esta composição pode ser útil para conseguir compreender ainda mais a influência da experiência sobre o desempenho.

Os resultados deste estudo também possuem alguns pontos interessantes para públicos, como pesquisadores, fundadores e colaboradores de startups e investidores. Para os pesquisadores, os resultados apontam a ausência da relação das variáveis analisadas, o que contradiz diversos estudos organizacionais. Isso era um resultado esperado para o presente estudo, pois havia questionamentos se as variáveis ambientais e organizacionais, da forma como os estudos, avaliam organizações tradicionais e se podem não ter a mesma adequação para os modelos de negócio de base tecnológica como as startups.

Portanto, as startups possuem comportamento organizacionais e estratégicos diferentes, necessitando de estudos mais específicos. Diante disso, pesquisas futuras poderiam utilizar o mesmo objetivo deste estudo, com uma amostra maior e uma análise mais horizontal, com o intuito de identificar se as relações com o desempenho mudam a partir do aumento da maturidade da startup.

Os fundadores e colaboradores das startups podem utilizar os presentes resultados deste estudo para se organizarem internamente para observarem aspectos como as nuances de formalização da estrutura e processo direcionado para tomada de decisão estratégica, visando reduzir seus riscos. Seria possível também avançar na análise e identificar quais são as variáveis ambientais e organizacionais que podem mais afetar seu desempenho e gerenciá-las de perto, 
visto que as startups analisadas neste estudo não indicaram tal relação. Na criação de startups, importa também buscar fundadores e co-fundadores com maior experiência para agregar aos decisores, já que as startups analisadas em geral não possuíam experiência elevada.

Já para os empreendedores, os resultados podem ser um indicativo da importância da existência de investidores para as startups, não apenas pelo investimento em si, mas pela participação ativa destes nas tomadas de decisões estratégicas, considerando que a maioria das startups analisadas não contavam com investidores.

Como principais limitações desta pesquisa, é importante listar: a amostra pequena, gerando um baixo poder estatístico; não ter identificado e categorizado as startups por maturidade do modelo de negócio; e não ter abordado os recursos físicos e financeiros como uma variável importante na relação com o desempenho.

Estudos futuros relacionados ao desempenho de startups deveriam considerar uma pesquisa longitudinal, a qual permitiria observar com maior precisão como ocorrem as relações ao longo do tempo, à medida que as startups amadurecem e crescem o seu modelo de negócio. E então, desenvolver as teorias organizacionais mais focadas no comportamento e necessidades das startups.

\section{Referências:}

ALDRICH, H. E.; PFEFFER, J. Environments of Organizations. Annual Review of Sociology, v. 2, p. 79-105, 1976.

ANSOFF, H. I. The New Corporate Strategy. New York: Wiley, 1988. p. 288.

ATINC, G.; OCAL, Y. The Moderating Effect of Organizational Environment on PostIPO Corporate Governance Change and Firm Performance Relationship. Journal of Leadership \& Organizational Studies, p. 1-13, 2014.

BANKER, R. D.; POTTER, G.; SRINIVASAN, D. An Empirical Investigation of an Incentive Plan that Includes Nonfinancial Performance Measures. The Accounting Review, v. 75, n.1, p. 65-92, 2000.

BARNEY, J. Firm Resources and Sustained Competitive Advantage. Journal of Management, v. 17, n. 1, p. 99-120, 1991.

BARON, R. A. Opportunity of Recognition: A cognitive perspective. Academy of Management Best Conference Paper, p. 1-7, 2004.

MIRANDA, J. Q.; SANTOS JUNIOR, C. D.; DIAS, A. T.. A influência das variáveis ambientais e organizacionais no desempenho de startups. Revista de Empreendedorismo e Gestão de Pequenas Empresas, v.5, n.1, 2016. 
BARON, R. M.; KENNY, D. A. The moderator-mediator variable distinction in social psychological research: conceptual, strategic, and statistical considerations. Journal of Personality and Social Psychology, v. 51, n. 6, p. 1173-1182, 1986.

BLANK, S.; DORF, B. The Startup Owner's Manual: The Step-By-Step Guide for Building a Great Company. [S.I.]: K \& S Ranch, 2014.

BOLLEN, K.; LENNOX, R. A conventional wisdom on Measurement: A Structural Equation Perspective. Psychological Bulletin, v. 110, n. 2, p. 305-314, 1991.

BRIGIDI, G. M. Criação de Conhecimento em Empresas Start-up de Alta Tecnologia. 179 f. Dissertação (Mestrado em Administração) - Universidade Federal do Rio Grande do Sul, Porto Alegre, 2009.

BURNS, T.; STALKER, G. M. The management of innovation. London: Tavistock Publications, 1961.

CASSAR, G. Industry and startup experience on entrepreneur forecast performance of new firms. Jounal of Business Venturing, v.29, n.1, p. 137-151, 2014.

CHANDLER, G. N. Business similarity as a moderator of the relationship between pre-ownership experience and venture performance. Entrepreneurship Theory and Practice, v. 20, n. 3, p. 51-65, 1996.

CHANDLER, G. N.; HANKS, S. H. Market Attractiveness, resource-based capabilities, ventures strategies, and venture performance. Journal of Business Venturing, v. 9, n.4, p. 331-349, 1994.

CHILD, J. Organizational structure, environment and performance: the role of strategic choice. Sociology, v.6, n. 1, p. 1-22, 1972.

CHIN, W. Issues and opinion on structural equation modeling. MIS Quarterly, v. 1, p. 22, 1998.

DELMAR, F.; SHANE, S. Does Business Planning Facilitate the development of new ventures? Strategic Management Journal, v. 24, n. 12, p. 1165-1185, 2003.

DRAGHICI, A.; POPESCU, A. D.; GOGAN, L. M. A proposed model for monitoring organizational performance. Social and Behavioral Sciences, v. 124, p. 544-551, 2014.

DUNCAN, R. B. Characteristics of Organizational Environments and Perceived Environmental Uncertainty. Administrative Science Quarterly, v. 17, n. 3, p. 313327, 1972.

DUNCAN, R. What is the right organziation structure? Decision tree analysis provide the answer. Organizational Dynamics, v.7, n.3, p. 59-80, 1979.

MIRANDA, J. Q.; SANTOS JUNIOR, C. D.; DIAS, A. T.. A influência das variáveis ambientais e organizacionais no desempenho de startups. Revista de Empreendedorismo e Gestão de Pequenas Empresas, v.5, n.1, 2016. 
ENTRIALGO, M. The impact of the alignment of strategy and managerial characteristics on Spanish SMEs. Journal of Small Business Management, v.40, n. 3, p. 260-270, 2002.

ESCRIBÁ-ESTEVE， A.; SÁNCHEZ-PEINADO， L.; SÁNCHES-PEINADO, E. Moderating Influences on the Firm's Strategic Orientation-Performance Relationship. International Small Business Journal, v. 26, n. 4, p. 463-489, 2008.

FERREIRA, M. P. et al. Gestão por indicadores de desempenho: resultados na incubadora empresarial tecnológica. Produção, v. 18, n.2, p. 302-318, 2008.

FINANCIADORA DE PROJETOS E PESQUISA (FINEP). Glossário de Termos e Conceitos.

em:

$<$ http://www.finep.gov.br/o_que_e_a_finep/conceitos_ct.asp >.

FOO, C. T.; LEE, T. S. The neural firm: Burns and Stalker in Extenso. The Jounal of High Technology Management Research, v.13, n. 2, p. 299-319, 2002.

FORBES. What is a startup. Disponível em: $<$ http://www.forbes.com/sites/natalierobehmed/2013/12/16/what-is-a-startup/>.

Acesso em: 31 jul. 2014.

FOWLER JR, F. Survey Research Methods (Applied Social Research Methods). 5a. ed. [S.I.]: SAGE Publications, 2013. p. 184.

FREDRICKSON, J. W. The Comprehensiveness of Strategic Decisions Processes: Extension, Observations, Future Directions. Academy of Management Journal, v. 27, n. 3, p. 445-466, 1984.

FREDRICKSON, J. W. The strategic decision process and organizational structure. Academy of Management Review, v. 11, n. 2, p. 280-297, 1986.

GABRIELSSON, J. Correlates of Boards Empowerment in Small Companies. Entrepreneuship Theory and Practice, v. 31, n. 5, p. 687-711, 2007.

HAIR, J. F. et al. Análise Multivariada de Dados. 6. ed. São Paulo: Bookman Companhia Editora Ltda., 2009.

HAMBRICK, D. C.; MASON, P. A. Upper Echelons: The Organization as a Reflection of Its Top Managers. The Academy of Management Review, v. 9, n. 2, p. 193-206, 1984.

HANNAN, M. T.; FREEMAN, J. The Population Ecology of Organizations. American Journal of Sociology, p. 929-964, 1977.

MIRANDA, J. Q.; SANTOS JUNIOR, C. D.; DIAS, A. T.. A influência das variáveis ambientais e organizacionais no desempenho de startups. Revista de Empreendedorismo e Gestão de Pequenas Empresas, v.5, n.1, 2016. 
HAYWARD, M. L. A. et al. Beyond hubris: How highly confident entrepreneurs rebound to venture again. Jounal of Business Venturing, v. 25, n. 6, p. 569-578, 2010.

HMIELESKI, K. M.; BARON, R. A. When does entrepreneurial self-efficacy enhance versus reduce firm performance? Strategic Entrepreneurship Journal, v. 2, n. 1, p. $57-72,2008$.

HMIELESKI, K. M.; ENSLEY, M. D. A contextual examination of new venture performance: entrepreneur leadership behavior, top management team heterogeneity, and environmental dynamism. Jounal of Organizational Behavior, v. 28, n. 7, p. 865-889, 2007.

HULL, F.; HAGE, J. Organizing for Innovation: Beyond Burns and Stalker's Organic Type. Sociology, v. 16, n. 4, p. 564-577, 1982.

JABNOUN, N.; KHALIFAH, A.; YUSUF, A. Environmental Uncertainty, Strategic Orientation and Quality Management: A Contingency Model. ASQ, v. 10, n. 4, p. 1731, 2003.

JAMES, H.; BARNES, J. Cognitve biases and their impact on strategic planning. Strategic Management Journal, 5, n. 2, 129-137, 2006.

KENNERLY, M.; NEELY, A. A framework of the factors affecting the evolution of performance measurement systems. International Journal of Operations \& Production Management, v. 22, n. 11, p. 1222-1245, 2002.

LIEBERMAN, M. B.; MONTGOMERY, D. B. First-movers Advantages. Strategic Management Journal, v. 9, n. S1, p. 41-58, 1988.

MELNYKA, S. A. et al. Is performance measurement and management fit for the future? Management Accounting Research, v. 25, n. 2, p. 173-186, 2014.

MILES, R.; SNOW, C. Organizational Strategy, Structure, and Process. New York: McGraw-Hill, 1978.

MINATOGAWA, V. L. Estudo e Adaptação de um método de gestão de desempenho de modelos de negócios em uma empresa nascente de base tecnológica (startup). Dissertação, Unicamp, Campinas, 2013.

MINTZBERG, H. Patterns in Strategy Formation. Management Science, v. 24, n. 9, p. 934-948, 1978.

MINTZBERG, H. The structuring of organizations: A Synthesis of the Research. Prentice Hall, 1979.

MINTZBERG, H.; RAISINGHANI, D.; THEORET, A. The Structure of "unstructured" decision processes. Administrative Science Quarterly, p. 246-275, 1976.

MIRANDA, J. Q.; SANTOS JUNIOR, C. D.; DIAS, A. T.. A influência das variáveis ambientais e organizacionais no desempenho de startups. Revista de Empreendedorismo e Gestão de Pequenas Empresas, v.5, n.1, 2016. 
MORRIS, M.; SCHINDEHUTTE, M.; ALLEN, J. The entrepreneur's business model: toward a unified perspective. Journal of Business Research, v. 58, n. 6, p. 726735, 2005.

MUELLER, G. C.; MONE, M. A.; BANKER, V. L. Formal Strategic Analyses and Organizational Performance: Decomposing the Rational Model. Organizational Studies, v. 28, n. 6, p. 853-883, 2007.

MURMANN, J. P.; SARDANA, D. Successfull entrepreneurship minimize risk. Australian Journal of Management, v. 38, n.1, p. 191-215, 2013.

OE, A.; MITSUHASHI, H. Founders' experiences for startups' fast break-even. Jounal of Business Research, v. 66, n. 1, p. 2193-2201, 2013.

PAPADAKIS, V. M.; BARWISE, P. How Much do CEOs and Top Managers Matter in Strategic Decision-Making? British Jounal Management, v. 13, n.1, p. 83-95, 2002.

PORTER, M. E. Competitive strategy. New York: Free Press, 1980.

PORTER, M. E. Towards a Dynamic Theory of Strategy. Strategic Management Journal, v. 12, n. S2, p. 95-117, 1991.

READ, S.; SONG, M.; SMIT, W. A meta-analytic review of effectuation and venture performance. Journal of Business Venturing, v. 24, n. 6, p. 573-587, 2009.

RIES, E. The Lean startup: How Today's Entrepreneurs use continuous innovation to create radically successfull businesses. [S.I.]: Random House LLC, 2011.

ROCHA, F. B. Proposta de modelo para geração de valor substancial e estratégia de crescimento acelerado em startups. 2008. 107 f. Dissertação (Mestrado em Administração de Empresas), Fundação Getúlio Vargas, São Paulo, 2008

SARASVATHY, S. D. Effectuation: Elements of Entrepreneurial Expertise. [S.I.]: Edward Elgar Pub, 2008. p. 368.

SEBRAE. O que é uma empresa startup. Disponível em: <https: //www.sebraemg.com.br/atendimento/bibliotecadigital/documento/Texto/O-que-euma-empresa-startup>. Acesso em: 15 out. 2014.

SIMON, M.; HOUGHTON, S. M.; AQUINO, K. Cognitive Biases, Risk Perception, and Venture Formation: How individuals decide to start companies. Journal of Business Venturing, v. 15, n. 2, p. 113-134, 1999.

SIMONS, T.; PELLED, L. H.; SMITH, K. A. Making use of difference: Diversity, debate, and decision comprehensiveness in top management teams. Academy of Management Journal, v. 42, n. 6, p. 662-673, 1999.

MIRANDA, J. Q.; SANTOS JUNIOR, C. D.; DIAS, A. T. . A influência das variáveis ambientais e organizacionais no desempenho de startups. Revista de Empreendedorismo e Gestão de Pequenas Empresas, v.5, n.1, 2016. 
SINE, W. D.; MITSUHASHI, H.; KIRSCH, D. A. Revisiting Burns \& Stalker: Formal Structure and new venture performance in emerging economic sectors. The Academy of Management Journal, v. 49, n. 1, p. 121-132, 2006.

SINK, S. D.; TUTTLE, T. C. Planejamento e medição para performance. Rio de Janeiro: Qualitymark, 1993.

STARTUPI. Você sabe o que é uma startup? Disponível em: <http: //startupi.com.br/2014/09/e-entao-o-que-e-uma-startup/>. Acesso em: 15 out. 2014.

STINCHCOMBE, A. L. Social structure and social organization. The handbook of organizations, Chicago, IL, 1965. p. 142-193.

STRODOMSKYTE, I.; DAI, X.; HAUGE, S. "All you need is trust" - to overcome the liability of newness by forming alliances. $101 \mathrm{f}$. MSc (Innovation and Entrepreneurship), University of Oslo, 2012.

STUART, R.; ABETTI, P. A. Startup Ventures: Towards the prediction of initial success. Jounal of Business Venturing, v. 2, n. 3, p. 215-230, 1987.

THOMPSON, J. D. Organizations in Action: Social Science Bases of Administrative Theory. New Jersey: New Brunswick, 1967.

VENKATRAMAN, N. Strategic Orientation of Business Enterprise: The Construct, Dimensionality, and Measurement. Management Science, v. 35, n. 8, p. 942-962, 1989.

WONG, K. K. K. Partial Least Squares Structural Equation Modeling (PLS-SEM) Techniques Using SmartPLS. Marketing Bulletin, v. 24, n. 1, p. 1-32, 2013. 